\title{
Different IOP, different diseases?
}

Michele lester, Elisa D’Alessandro

Anatomical-Clinical Laboratory for Functional Diagnosis and Treatment of Glaucoma and Neuro-ophthalmology, Eye Clinic, DINOGMI, University of Genoa, Genoa, Italy

Glaucoma is a chronic, progressive disease characterized by typical optic nerve head changes and visual field defects. These alterations are caused by an intraocular pressure (IOP) being too high for the wellbeing of the specific optic disc. ${ }^{1}$ Typical clinical findings in glaucoma patients include thinning of the optic disc rim (Fig. 1), loss of retinal nerve fibers in the inferior sector with subsequent visual field defects in the superior sector.

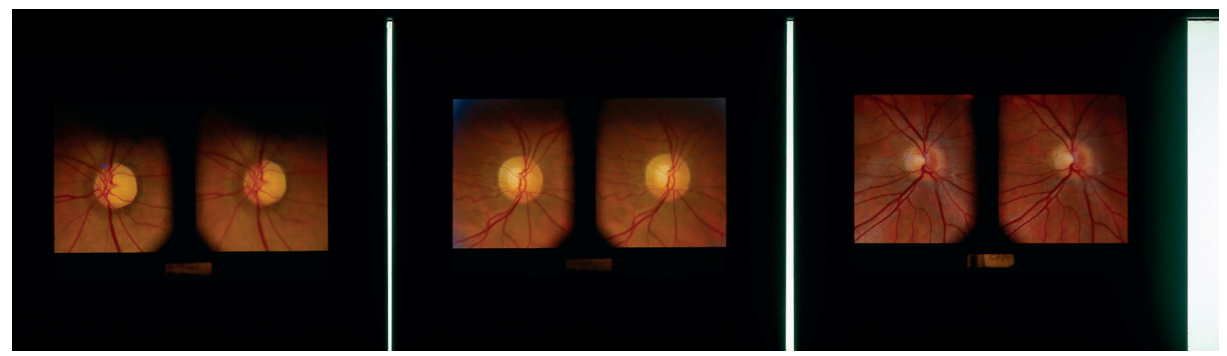

Fig. 1. Early glaucomatous ONH. The inferior rim is thinner than normal one.

The IOP of the eye is determined by the balance between the amount of aqueous humor that the eye makes and the ease with which it leaves the eye. The Goldmann equation states: $\mathrm{Po}=(\mathrm{F} / \mathrm{C})+\mathrm{Pv}$; Po is the IOP in millimeters of mercury $(\mathrm{mmHg}), \mathrm{F}$ is the rate of aqueous formation, $\mathrm{C}$ is the facility of outflow, and $\mathrm{PV}$ is the episcleral venous pressure. ${ }^{2}$

As instruments were being developed for more objective measurement of IOP, population surveys at that time found that only approximately two percent of the population had IOP levels above $21 \mathrm{mmHg}{ }^{3}$

From the literature we know that the mean IOP in the general population varies between 16 and $17 \mathrm{mmHg}$ with the upper $95 \%$ confidence interval being $21 \mathrm{mmHg} .{ }^{4}$

Correspondence: Michele lester, MD, PhD, University Eye Clinic, Viale Benedetto XV, 5, 16132 Genoa, Italy. E-mail: iester@unige.it. 
For many years, the cut-off value of $21 \mathrm{mmHg}$ has helped physicians in classifying healthy subjects from glaucomatous patients and ocular hypertension. In the 1960's, Armaly organized in a collaborative investigation of 'ocular hypertensive patients' with intraocular pressure greater than $21 \mathrm{mmHg}$, but without optic nerve damage or visual loss, Armaly found that the majority of patients in his study did not develop visual field loss over a seven-year period. ${ }^{5}$

IOP value is also used to classified primary open-angle glaucoma (POAG) into having high-tension glaucoma (HTG) or normal-tension glaucoma (NTG). According to the European Glaucoma Society Guidelines, both groups present the same signs and symptoms: initial asymptomatic disease until visual field loss is advanced, typical changes in the optic nerve head, and subsequenttypical alterations of the visual field. NTG patients present these typical changes while presenting a normal IOP (i.e., $<21 \mathrm{mmHg}$ ) in contrast to HTG patients who present an IOP of $>21$ $\mathrm{mmHg}$ without treatment. ${ }^{1}$ When evaluating IOP through applanation tonometry it is important to keep corneal thickness, elasticity and structure in mind as the tonometer assumes the central corneal thickness to be $520 \mu \mathrm{m}$ with minimal variations. ${ }^{6}$ However, if the cornea is thinner it is probable that the IOP be underestimated, and if thicker, an overestimation is more likely. At present, no formula is available for calculating a correct IOP based on corneal thickness. ${ }^{7}$

In particular, for each $10 \mu \mathrm{m}$ change in central corneal thickness (CCT), the change in the IOP reading could range from 0.1 to $0.7 \mathrm{mmHg} .{ }^{8-10}$ Furthermore, the variability of Goldmann IOP measurements could depend on the thickness of the tear film, corneal astigmatism, the season, and the examiner's competence in IOP measurements. The CCT is not associated with refractive error, corneal curvature, anterior chamber depth, or axial length. It is an independent factor unrelated to other ocular parameters. ${ }^{11,12}$ Furthermore, the CCT can vary between glaucoma populations. For example, the Japanese eyes have thinner corneas than the Chinese and Filipino eyes; white, Chinese, Hispanic, and Filipino eyes have comparable CCT values; and the corneas of African Americans are significantly thinner. ${ }^{13}$

Corneal hysteresis might also interfere with IOP measurements, although it is not clear what it measures; it appears as though this corneal variable describes the response of the cornea to rapid deformation. Congdon et al. suggest that the relationship between glaucoma and corneal features is more complex than simple anatomic thickness. ${ }^{14}$

Astigmatism, direction of gaze, and tear thickness are clinically important sources of error in Goldmann applanation tonometry. In a model comparing tonometers with the mean IOP value, the Goldmann tonometer was least affected by differences in CCT and the Tono-Pen was least affected by differences in hysteresis. ${ }^{15}$

With regard to NTG we can identify two main opinions regarding the disease. Many authors ${ }^{16-24}$ define NTG as being a particular subtype of glaucoma presenting typical glaucomatous optic nerve head damage and visual field defects. These include inferior rim loss, paracentral scotoma, and peripapillary hemorrhages. On the other 
hand, another group of authors believe NTG and HTG to be the same disease..$^{25-32}$

In a recent study, ${ }^{32}$ the aim of which was 'to determine whether the patterns of visual field damage between HTG and NTG are equivalent', lester et al. did not find any difference in the pointwise analysis between the two nor any difference in paracentral areas as was described in other studies. Furthermore, Drance et al. were able to subdivide glaucoma patients based on the characteristics of the optic disc. More specifically, in a paper co-authored by Drance and Nicolela, four different subgroups were identified based on the appearance of the optic disc: focal ischemic, senile sclerotic, myopic and concentric enlargement. ${ }^{33}$ For each group different, statistically significant risk factors were identified, for instance: focal ischemic patients were younger with a localized typical visual field damage, mainly female with migraine or Raynoud syndrome and lower IOP, on the other hand concentric enlargement patients were older with higher IOP and typical visual field defect.

Another study conducted by Drance and Schultzer analyzed different clinical risk factors in a population composed of both patients with NTG and HTG (risk factors included age, gender, mean IOP, anticardiolipin antibody, HDL, LDL, etc.). ${ }^{34}$ Multivariate analysis revealed two statistically different clusters of patients with NTG and HTG cases equally distributed. The two clusters showed different risk factors associated, therefore showing that IOP is fundamental but not the sole factor necessary in distinguishing NTG from HTG. ${ }^{34}$

When patients present with typical glaucomatous optic disc, visual field and high IOP diagnosis of HTG is very simple. On the other hand, in the presence of normal IOP, with the same clinical characteristics, diagnosis is not as easy. Diseases other than NTG must therefore be taken in consideration. These include optical nerve head coloboma, congenital optic nerve head pit and tilted optic nerve head and arteritic anterior ischemic optic neuropathy which in the chronic phase can have a large cupping outlining that ischemic disease can change the optic nerve hypoplasia $(\mathrm{ONH})$ color after the acute moment, but with time the degeneration of ganglion cells and astroglia can cause a loss of tissue with an increase of cupping.

Before diagnosing NTG, it is important to assess other possible causes which may determine otherwise pseudo-glaucomatous alterations. One of the structures to evaluate is the visual pathway from the retina to the cortex..$^{35}$ In a study, conducted by lqbal et al., ${ }^{36}$ the prevalence of intracranial compressive lesions in NTG and HTG were compared through the use of MRI. A statistically significant difference between the two was found with four of the NTG patients having clinically significant intracranial compressive lesions compared to none in the HTG group $(p=0.039)$. The identification of these lesions therefore excluded the diagnosis of NTG, even though the patients presented with typical optic disc and visual field anomalies, making evaluation of the visual pathway important in the normal work-up of these patients. In the latter paper, Iqbal et al. showed atypical chiasmatic lesions which could mimic typical glaucomatous optic disc lesions. ${ }^{36}$

A further evaluation which is needed is the assessment of the progression of 
the disease, as glaucoma is, by definition, progressive. Therefore close follow-up is mandatory in these patients in order to identify an ongoing decline in the visual field or structure of the optic disc. It has been shown that at least three visual field tests per year for at least two years is necessary to assess the rate of progression of glaucomatous patients. ${ }^{37}$ Other neuro-ophthalmological diseases can develop a visual field damage but usually the rate of progression is different: in the anterior ischemic optic neuropathy (AION) the progression, if it happens, is 'a poussée', or there is not a correlation between ONH damage and, in particular, cupping appearance and visual field lesions. In POAG, usually, the loss of ganglion cells in ONH or in the retinal nerve fiber imaging (RNFL) is well-localized and correlated to visual field defect.

No very specific or sensitive factor has been identified to predict optic nerve head cupping in glaucomatous patients or ONH change in non-glaucomatous patients. ${ }^{35}$

In conclusion, NTG and HTG seem to be very similar diseases with IOP being the main differentiating factor. Different types of glaucoma exist and are probably based on presence of different risk factors, however, differential diagnosis is fundamental when considering NTG.

\section{Acknowledgment}

This research received no specific grant from any funding agency in public, commercial or not-for-profit sectors. None of the authors has proprietary interest in the development and marketing of any products mentioned in the article.

\section{References}

1. European Glaucoma Society. Terminology and Guidelines for Glaucoma. Ch. 2. Savona: Dogma 2003.

2. American Academy of Ophthalmology. Basic and Clinical Science Course Section 10: Glaucoma. Singapore: American Academy of Ophthalmology 2008.

3. Colton T, Ederer F. The distribution of intraocular pressures in the general population. Surv Ophthalmol 1980;25(3):123-129.

4. Alimuddin M. Normal intra-ocular pressure. Br J Ophthalmol 1956;40(6):366-372.

5. Armaly MF. On the distribution of applanation pressure and arcuate scotoma. In: Patterson G, Miller SJ, Patterson GD (eds.), Drug Mechanisms in Glaucoma. Boston, MA: Little, Brown 1966.

6. Goldmann H, Schmidt T. Über Applanationstonometrie. Ophthalmologica 1957;134:221-242

7. lester M, Mete M, Figus M, Frezzotti P. Incorporating corneal pachymetry into the management of glaucoma. J Cataract Refract Surg 2009;35:1623-1628.

8. Doughty MJ, Zaman ML. Human corneal thickness and its impact on intraocular pressure measures: a review and meta-analysis approach. Surv Ophthalmol 2000;44:367-408.

9. Kniestedt C, Lin S, Choe J, et al. Clinical comparison of contour and applanation tonometry and their relationship to pachymetry. Arch Ophthalmol 2005;123:1532-1537.

10. Tonnu P-A, Ho T, Newson T, et al. The influence of central corneal thickness and age on intraocular pressure measured by pneumotonometry, non-contact tonometry, the Tono-Pen XL, and Goldmann 
applanation tonometry. Br J Ophthalmol 2005;89:851-854.

11. Chen M-J, Liu Y-T, Tsai C-C, et al. Relationship between central corneal thickness, refractive error, corneal curvature, anterior chamber depth and axial length. J Chin Med Assoc 2009;72:133-137.

12. Shimmyo M, Orloff PN. Cornea thickness and axial length. Am J Ophthalmol 2005;139:553-554.

13. Aghaian E, Choe JE, Lin S, Stamper RL. Central corneal thickness of Caucasians, Chinese, Hispanics, Filipinos, African Americans, and Japanese in a glaucoma clinic. Ophthalmology 2004;111:2211-2219.

14. Congdon NG, Broman AT, Bandeen-Roche K, Grover D, Quigley HA. Central corneal thickness and corneal hysteresis associated with glaucoma damage. Am J Ophthalmol 2006;141:868-875.

15. Broman AT, Congdon NG, Bandeen-Roche K, Quigley HA. Influence of corneal structure, corneal responsiveness, and other ocular parameters on tonometric measurement of intraocular pressure. J Glaucoma 2007; 16:581-588.

16. Tuulonen A, Airaksinen PJ. Optic disc size in exfoliative, primary open angle, and low tension glaucoma. Arch Ophthalmol 1992;110:211-213.

17. Caprioli J, Spaeth GL. Comparison of the optic nerve head in high- and low-tension glaucoma. Arch Ophthalmol 1985;103:1145-1149.

18. Greve EL, Geijssen HC. The relation between excavation and visual field in glaucoma patients with high and with low intraocular pressure. Doc Ophthalmol Proc Ser 1983;35:35-42.

19. Anderton S, Hitchings RA. A comparative study of visual fields of patients with low tension glaucoma and those with chronic simple glaucoma. Doc Ophthalmol Proc Ser 1983;35:97-99.

20. Chauhan BC, Drance SM, Douglas GR, Johnson CA. Visual field damage in normal tension and high tension glaucoma. Am J Ophthalmol 1989;108:636-642.

21. Drance SM. The visual fields of low tension glaucoma and shock-induced optic neuropathy. Arch Ophthalmol 1977;95:1359-1361.

22. Fazio $P$, Krupin T, Feitl ME, Werner EB, Carrè DA. Optic disc topography in patients with low-tension and primary open angle glaucoma. Arch Ophthalmol 1990;108:705-708.

23. Yamagami J, Araie M, Shirato S. A comparative study of optic nerve head in low- and high-tension glaucomas. Graefe's Arch Clin Exp Ophthalmol 1992;230:446-450.

24. Samuelson TW, Spaeth GL. Focal and diffuse visual field defects: their relationship to intraocular pressure. Ophthalmic Surg 1993;24:519-525.

25. Motolko M, Drance SM, Douglas DR. The visual field defects of low-tension glaucoma. In Greve EL, Heijl A (eds.),Fifth International Visual Field Symposium, pp. 107-111. The Hague, Dr W Junk NV Publishers 1983.

26. Lewis RA, Hayreh SS, Phelps CD. Optic disc and visual field correlations in primary open-angle and low-tension glaucoma. Am J Ophthalmol 1983;96:148-152.

27. Motolko M, Drance SM, Douglas GR. Visual field defects in low tension glaucoma. Comparison of defects in low tension glaucoma and chronic open angle glaucoma. Arch Ophthalmol 1982;100:10741077.

28. King D, Drance SM, Douglas GR, Schulzer M, Wijsman K. Comparison of visual field defects in normal-tension glaucoma and high-tension glaucoma. Am J Ophthalmol 1986;101:204-207.

29. Miller KM, Quigley HA. Comparison of optic disc features in low-tension and typical open-angle glaucoma. Ophthalmic Surg 1987;18:882-889.

30. lester M, Mikelberg FS. Optic nerve head morphologic characteristics in high-tension and normal-tension glaucoma. Arch Ophthalmol 1999;117:1010-1013.

31. lester M, Swindale NV, Mikelberg FS. Sector-based analysis of optic nerve head shape parameters and visual field indices in healthy and glaucomatous eyes. J Glaucoma 1997;6:371-376.

32. lester M, DeFeo F, Douglas GR. Visual field loss morphology in high- and normal-tension glaucoma. J Ophthalmol 2012;2012:327326. (Epub 2012 Feb 8)

33. Nicolela MT, Drance SM. Various glaucomatous optic nerve appearances: clinical correlations. Ophthalmology 1996;103:640-649.

34. Schulzer M, Drance SM, Carter CJ, Brooks DE, Douglas GR, Lau W. Biostatistical evidence for two distinct chronic open angle glaucoma populations. Br JOphthalmol 1990;74:196-200. 
35. Greenfield DS, Siatkowski RM, Glaser JS, Schatz NJ, Parrish RK 2nd. The cupped disc. Who needs imaging? Ophthalmology 1998;105:1866-1874

36. Ahmed IIK, Feldman F, Kucharrczyk W, Trope GE. Neuroradiologic screening in normal-pressure glaucoma: study results and literature review. J Glaucoma 2002;11:279-286.

37. Chauhan BC, Garway-Heath DF, Goñi FJ, et al. Practical recommendations for measuring rates of visual field change in glaucoma. Br J Ophthalmol. 2008;92(4):569-573. 